\title{
O OLHAR CAMILIANO SOBRE O CONTEXTO LITERÁRIO OITOCENTISTA: \\ METALINGUAGEM E PARÓDIA EM O QUE FAZEM MULHERES
}

\author{
Luciene Marie Pavanelo ${ }^{1}$
}

RESUMO: Tendo vivido durante o apogeu do Romantismo, seguido do Realismo, Camilo Castelo Branco não poderia deixar de revelar um olhar crítico perante seu contexto literário. No romance $O$ que fazem mulheres (1858), encontramos este olhar a partir da análise dos procedimentos metalingüísticos e paródicos, utilizados pelo autor como uma forma de distinguir a sua obra do restante da produção oitocentista vigente.

PALAVRAS-CHAVE: Camilo Castelo Branco; metalinguagem; paródia; ironia.

\begin{abstract}
Having lived during the apogee of Romanticism, followed by Realism, Camilo Castelo Branco could not abstain from revealing a critical view upon his literary context. In the novel $O$ que fazem mulheres (1858), we find this view through the analysis of metalinguistic and parody procedures, used by the author as a form of distinguishing his work from the rest of the $19^{\text {th }}$ century production in vogue.
\end{abstract}

KEYWORDS: Camilo Castelo Branco; metalanguage; parody; irony.

\footnotetext{
${ }^{1}$ Mestranda do Programa de Pós-Graduação em Literatura Portuguesa da Universidade de São Paulo (USP) e bolsista da Fundação de Amparo à Pesquisa do Estado de São Paulo (FAPESP).
} 
Camilo Castelo Branco viveu o conturbado período de transição entre o Romantismo e o Realismo em suas quase quatro décadas dedicadas à produção literária. Escritor entre dois mundos (Cf. LOURENÇO, 1994), não parecia pertencer a nenhum, dirigindo suas críticas ora aos exageros da estética romântica, ora ao cientificismo da escola realista.

Procuraremos abordar, neste artigo, o romance camiliano como uma fonte de estudo do olhar de seu autor sobre o contexto literário oitocentista. Nele é possível depreendermos uma "teoria camiliana da ficção narrativa", como explica Aníbal Pinto de Castro:

\begin{abstract}
Encontramos (...) disseminados por toda a sua obra (...) abundantes e importantes elementos que permitem sistematizar essa teoria, não como um cânone imutável, antes como uma concepção em permanente mudança (...), atenta às transformações que a arte do romance viera sofrendo (...). Camilo foi um crítico literário de fina argúcia e seguro sentido estético (...). O exercício dessa crítica não se verificou tanto através das posições ou juízos expressos em textos propositadamente escritos para se pronunciar sobre obras de ficção e publicados em jornais ou revistas (...), mas principalmente em prefácios ou outras formas de paratexto às suas novelas, em intromissões justificativas dos narradores (...), ou até em intervenções das próprias personagens, muitas vezes deliberadamente investidas na função de servirem de porta-voz a essa teoria fragmentária. (CASTRO, 1991, p.53-54).
\end{abstract}

Analisaremos aqui um dos romances de atualidade, da primeira década da produção camiliana, escrito antes do sucesso de Amor de Perdição, época em que Jacinto do Prado Coelho denomina de "conversão ao natural", na qual "multiplicam-se nas novelas de Camilo os protestos de fidelidade ao real" (COELHO, 1946, p.285). $O$ que fazem mulheres foi publicado em 1858, mas teria sido escrito em 1856, "a acreditarmos na indicação do autor nas Memórias do Cárcere” (COELHO, 1946, p.285).

O que nos importa pontuar é que Portugal vivia nesse momento o auge do ultraromantismo. Como sabemos, ao mesmo tempo em que o folhetim romântico era largamente consumido, a França já assistia à disseminação das teorias positivistas e dos tratados de fisiologia, que iriam servir de base para o surgimento da escola realista devemos lembrar que Madame Bovary fora publicado justamente nesse período. 
O discurso cientificista, embora ainda não reinante em Portugal, já começava a aparecer nas rodas intelectuais - e será alvo da paródia camiliana, da mesma forma que o discurso romântico, como veremos mais adiante.

O que fazem mulheres traz em seu subtítulo a designação "romance filosófico", uma primeira pista que pode vir a ser útil em nossa leitura. Prado Coelho afirma que "é fácil tirar das novelas camilianas centenas de máximas que exprimem uma filosofia da vida (...). São as idéias gerais sobre o homem que permitem a Camilo classificar de 'filosóficas' algumas de suas novelas ( $O$ que fazem mulheres, por exemplo)" (COELHO, 1983, p.255-256).

Além de uma "filosofia da vida", é possível depreendermos também uma "filosofia da literatura", como buscaremos demonstrar ao longo deste artigo.

Ao classificar o seu romance como "filosófico", Camilo demonstra o interesse em fazer o leitor não apenas consumir a obra, mas refletir a partir dela. No final do primeiro prefácio da obra, denominado "A todos os que lerem”, Camilo expõe um parágrafo ambíguo, que pode ser compreendido de várias maneiras:

\footnotetext{
Não cuidem que podem ler um romance, logo que soletram. Precisamse mais conhecimentos para o ler que para o escrever. Ao autor bastalhe a inspiração, que é uma coisa que dispensa tudo, até o siso e a gramática. O leitor, esse precisa mais alguma coisa: inteligência; - e, se não bastar esta, valha-se da resignação. (CASTELO BRANCO, 1967, p.7).
}

Primeiramente, podemos depreender que o narrador zomba do discurso fisiologista da época, que exigia do leitor um conhecimento inútil de termos científicos. Isso porque esse parágrafo é precedido de outro, no qual parodia esse tipo de discurso: "O leitor sabe o que isto é? Já sentiu na alma o apertar dum cáustico? Excruciaram-no, alguma vez, os flagelos da inspiração corrosiva, como duas onças de sublimado? Se não sabe o que isto é, estude farmácia, abra um expositor de química mineral, e verá" (CASTELO BRANCO, 1967, p.7).

Por outro lado, pode ser também um ataque aos escritores de folhetins românticos - e, neste caso, o narrador-autor se coloca, ironicamente, como um deles -, que escrevem apenas pela "inspiração, que é uma coisa que dispensa tudo, até o siso e a gramática". Além disso, nessa passagem o narrador faz uma crítica ao leitor que acabou de aprender a soletrar, ou seja, que não consegue enxergar uma camada mais profunda 
de sua obra, resignando-se a apreender o seu enredo superficial - que, por sua vez, Camilo constrói para atender a esse mesmo leitor "menos inteligente".

Ainda nesse prefácio encontramos, como Paulo Franchetti aponta, um "discurso destinado, apesar da ironia, a atrair o leitor romântico" (FRANCHETTI, 2003, p.XXV). O capítulo inteiro é montado a partir desse discurso - claramente paródico -, merecendo uma leitura integral, da qual selecionaremos apenas o seu início:

É uma história que faz arrepiar os cabelos.

Há aqui bacamartes e pistolas, lágrimas e sangue, gemidos e berros, anjos e demônios.

É um arsenal, uma sarrabulhada, e um dia de juízo!

(...) Há aí almas de pedra, corações de zinco, olhos de vidro, peitos de asfalto?

Que venham para cá.

Aqui há cebola para todos os olhos;

Broca para todas as almas;

Cadinhos de fundição metalúrgica para todos os peitos.

Não se resiste a isto. Há-de chorar toda a gente, ou eu vou contar aos peixes, como o padre Vieira, este miserando conto. (CASTELO BRANCO, 1967, p.5-6).

Ao mesmo tempo em que utiliza um palavreado repleto de lugares-comuns apreciados pelos leitores de folhetins românticos, Camilo ridiculariza esses mesmos procedimentos romanescos, fazendo uso da ironia apreciada pelo "leitor inteligente", cujo prazer tirado da leitura é de outra ordem. Wayne Booth $(1974$, p. 28) explica que o autor irônico é mais interessante para esse leitor porque pressupõe que este tenha um tipo de sabedoria, a capacidade de compreender a ironia: ele assume ser desnecessário explicar nos mínimos detalhes as verdades ocultas, mas compartilhadas entre ambos, cujo significado o leitor deve reconstruir sozinho.

Em seguida, Camilo apresenta um segundo prefácio, intitulado "A alguns dos que lerem", dirigido a outro tipo de leitor: aquele que procura lições edificantes e defende um ideal moralizante de literatura.

O narrador-autor defende a escrita de um "romance filosófico" e moral, questionando, com certa afetação - provavelmente irônica - se "não será uma ação meritória emoldurar-se em formas verossímeis a virtude, que os pessimistas acoimam de impraticável neste mundo?” (CASTELO BRANCO, 1967, p.9). E acrescenta, criticando - ou não - o leitor cético: "Hão-de só crer nas façanhas do crime, nas 
hipérboles da maldade humana, e negar as perfeições do espírito, descrer o que ultrapassa as balizas duma certa virtude convencional, que não custa dores a quem a usa?” (CASTELO BRANCO, 1967, p.9).

Após esses dois prefácios nos quais Camilo procura agradar a três tipos de leitores, o narrador-autor insere um "Capítulo Avulso. Para ser colocado onde o leitor quiser", que apresenta o personagem Francisco Nunes, o qual é inútil para a trama, exceto pelo fato de ter arremessado, sem querer, um charuto no quintal dos protagonistas do romance. Tal charuto acabaria por se tornar a "prova final", para o marido, do suposto adultério da jovem esposa.

De acordo com Franchetti, no momento em que o capítulo é lido, ou seja, antes de o leitor conhecer a trama, "só é possível a sua fruição como paródia: ou da precisão documental do romance realista, ou dos excessos emocionais da personagem romântica" (FRANCHETTI, 2003, p.XXVII).

O fortuito arremessador do charuto da discórdia é caracterizado ironicamente como um "rapaz [que] tinha talento demais para escrever folhetins líricos, e outras coisas", mas que "nunca escreveu, porque não queria assinar-se Nunes" (CASTELO BRANCO, 1967, p.11). Ao ridicularizar o nome do personagem - "Que nome tão peco e charro! Francisco Nunes! (...) Há apelidos que parecem os epitáfios dos talentos" (CASTELO BRANCO, 1967, p.11) - o narrador denuncia que para ter sucesso na época um escritor não poderia possuir um nome ordinário, ou seja, o nome do autor e a "propaganda" que se poderia fazer dele teria mais valor do que o conteúdo de sua obra.

Por outro lado, a passagem também pode ser compreendida de maneira inversa, uma vez que a ironia abre espaço para essa interpretação ambígua: se Francisco Nunes nunca escreveu, não foi devido ao seu nome não-artístico, mas sim devido à sua falta de talento.

Essa falta de talento pode ser vista ao longo do capítulo, no qual o personagem "vai (...) falando só, e falando, ao que parece enraivecido" (CASTELO BRANCO, 1967, p.12), destilando um discurso empolado, mas vazio, sobre os males do tabaco, responsável, segundo ele, pela degenerescência da civilização e de seu próprio corpo, descrito a partir dos lugares-comuns que caracterizam o herói byroniano: 
deviam vicejar as rosas da adolescência, adere aos ossos, desmedulados e cariados, uma tosse violenta lhe reteza os músculos do pescoço. (CASTELO BRANCO, 1967, p.17).

A imagem de vida desregrada dos ultra-românticos é ridicularizada pelo narrador a partir da própria voz de Francisco Nunes, que prossegue:

As faculdades intelectuais estão entorpecidas nesse mancebo. Estimulando-se com cognac e absinto, esta espécie de cretino, bestificado por uma enfermidade incurável, apenas consegue dizer três tolices acerca de Donizetti, sentado num mocho de botequim, encostando o corpo enervado à banca dos licores incitantes. (CASTELO BRANCO, 1967, p.17).

Ao mesmo tempo em que apresenta uma paródia dos lugares-comuns ultraromânticos, o discurso de Francisco Nunes é baseado na retórica cientificista que estava adentrando o meio intelectual da época, tão vazia quanto a retórica romântica:

Porque os vossos charutos, propinadores de venenos, enegrecem as substâncias orgânicas, como o ácido sulfúrico.

São amargos e cáusticos como o ácido nítrico.

Calcinam os beiços como o ácido hidroclórico.

Queimam a laringe como o ácido fosfórico.

Laceram o esôfago como o acetato de chumbo.

Fulminam e despedaçam como o ácido hidrociânico. (CASTELO BRANCO, 1967, p.14).

O narrador camiliano, por sua vez, não deixa de ridicularizar novamente esse tipo de literatura, afirmando ironicamente que "um 'manual de química para uso dos leitores de romances' é instantemente reclamado. Sente-se na literatura este vazio, desde que a novela é um estendal da ciência humana" (CASTELO BRANCO, 1967, p.14).

Iniciando a trama propriamente dita, encontramos um diálogo entre mãe e filha, no qual a primeira tenta convencer a segunda a casar-se por dinheiro e não por amor. A filha afirma que "ainda ontem [lera] um folhetim contra as mulheres que se deixam seduzir pela 'fortuna' de estúpidas criaturas" (CASTELO BRANCO, 1967, p.23), comentário esse que anuncia o próprio assunto do romance.

A mãe, por sua vez, argumenta que a realidade é diferente da ficção, e que os escritores dos folhetins, na vida real, também procuram um casamento que tenha um rico dote: "Vê lá se entre os folhetinistas aspirantes ao casamento de especulação se te 
depara o nome que ontem leste..." (CASTELO BRANCO, 1967, p.24). Nessa passagem, Camilo propõe o questionamento de seu próprio enredo, expondo a problemática relação entre ficção e realidade, aquilo que teoricamente o romance defenderia - o casamento por amor - e aquilo que realmente acontece na sociedade, não importando o que os hipócritas e os sonhadores diziam, o casamento por dinheiro.

Ainda no primeiro capítulo, temos a apresentação do personagem Ricardo de Sá, uma paródia do "homem fatal" romântico, mostrado na obra de forma rebaixada. Um exemplo desse rebaixamento é o comentário jocoso do narrador, que se segue a uma longa e minuciosa descrição de sua toilette: "a compostura airosa das lapelas do fraque, a última demão de escova, e o aprumo do chapéu, onde não há um fio eriçado, tolhem muitas vezes a saída do peralta, que se encontra com a terrina da sopa do jantar" (CASTELO BRANCO, 1967, p.27).

Zombando do discurso cientificista da época, o narrador ironicamente afirma que o bacharel, "convicto da excrescência espiritual, crê-se dotado de fluidos nérveos, magnetismo, eletricidade, eterização. Julga-se enfim anestésico, espasmódico, dinâmico, enfím tudo o mais que não se entende" (CASTELO BRANCO, 1967, p.27-28). A maneira segundo a qual afirma conquistar as mulheres é também ridicularizada pelo narrador:

\footnotetext{
Não ama as mulheres, pranteia-as como vítimas do seu poder fascinante. Algumas vezes, tem a piedade de as não encarar para as não abismar. Outras, exerce a crueza da experiência, fitando-as com o olho carregado de eletricidade, fala-lhes com um timbre magnético que ele sabe, e, não há que ver, o sonambulismo é pronto, a atração é irresistível como a da cobra-cascavel do Canadá após o tangedor de flauta.

Crê tudo isto o bacharel, e há velhacos que lho ouvem com a sisudeza da crença, e lhe não receitam um curativo de cáusticos. (CASTELO BRANCO, 1967, p.28).
}

O narrador, na maioria das vezes em que se refere a ele, denomina-o ironicamente de "o autor possível do SÉCULO PERANTE A CIÊNCIA" (CASTELO BRANCO, 1967, p.37), zombando da sua intenção de escrever um livro científico intenção que nunca conclui, como mostra o antepenúltimo parágrafo da história: "O bacharel Ricardo de Sá comprou mais três bengalinhas, e dá a última demão ao seu SÉCULO PERANTE A CIÊNCIA" (CASTELO BRANCO, 1967, p.182). Dessa forma, 
Camilo critica, rebaixando, não apenas o personagem, mas aquilo que ele representa: o intelectual romântico e o cientificista.

Ao final do capítulo III - no qual há a descrição impiedosa de João José Dias, o grotesco "brasileiro" que voltou a Portugal rico, velho, feio e gordo, e que viria a ser o marido da jovem Ludovina -, o narrador-autor pede ironicamente para seu editor, com o intuito de prevenir "uma crise literária no Brasil", para que ele acrescente um epílogo composto de várias virtudes (bom filho, honesto, trabalhador) que João José Dias teria:

Se pintei João José Dias feio, não é dele a culpa, nem minha. João José Dias era realmente muito feio. Do Brasil vem muita gente galante. Tenho na pasta um esboço de romance onde figuram quatro brasileiros bonitos. Hão-de ver com que isenção de ânimo se escreve nesta província das letras. (CASTELO BRANCO, 1967, p.46).

Aqui, mais uma vez, a escrita se torna assunto do diálogo entre narrador e leitor, numa "ironia emergente da ambigüidade das relações dialéticas entre vida e ficção, homem-autor e autor-inventor de histórias, vocação ou missão do escritor e negócio do livro" (COELHO, 1983, p.286).

Já no capítulo VIII, Camilo parodia o uso de reticências da literatura romântica, acrescentadas de uma auto-crítica irônica, na qual acusa os romancistas de encherem linhas para tornarem o livro maior e, portanto, mais caro: "Há reticências que não dizem nada. A literatura merceeira, para justificar o adjetivo, inventou as carreiras de reticências, as quais correspondem aos pesos roubados da mercearia. Eu abri loja, e vou com os outros" (CASTELO BRANCO, 1967, p.89).

O início do capítulo X, por sua vez, apresenta uma falsa defesa, claramente irônica, da poesia romântica, em contraponto com o materialismo da prosa: "se todos fizéssemos versos, e nos amássemos em oitava rima, eu lhes asseguro que este globo era um viveiro de anjos. A teoria de Hobbes seria uma calúnia, e a de Maltus um absurdo. Não andaríamos travados em permanente luta, nem a exuberância da propagação assustaria os economistas" (CASTELO BRANCO, 1967, p.96).

O narrador-autor aponta a falta de realismo neste tipo de literatura, acabando por fazer uma defesa implícita do romance capaz de mostrar a realidade social, ainda que tenha que se sujeitar às regras de mercado: "Havia só o risco de nos matar a fome; mas cada cisne teria um canto derradeiro com que esforçar a guerra à prosa que inventou os 
cereais, o boi cozido, as ações do banco, e a troca dum romance por quinhentos réis" (CASTELO BRANCO, 1967, p.96-97).

O capítulo XIII interrompe a ação para mostrar o diálogo entre o narrador-autor e quatro amigos literatos - pertencentes à esfera heterodiegética do romance - no qual discutem o fazer literário e o gosto do público.

Um dos amigos faz a acusação de que "os teus romances do meio em diante adivinham-se" (CASTELO BRANCO, 1967, p.133), e conta o suposto final da história, aos moldes do folhetim romântico. Nessa passagem, Camilo aproveita para zombar do público, frustrando as suas expectativas de encontrar um final folhetinesco, negando o estatuto ficcional de sua obra e reafirmando sua filiação ao real, jogo no qual o próprio romance oitocentista estava embasado: "Eu já disse em mais de um livro que não escrevo de fantasia. A verdade e a observação dispõem-me as situações como tu as não inventas. A natureza, que tu conheces, é tola, meu amigo" (CASTELO BRANCO, 1967, p.135).

Ainda nessa discussão entre realidade e ficção, no capítulo denominado "Conclusão" o narrador-autor faz uma crítica ao teatro dramático, que mostra a cura da loucura a partir de um lugar-comum exagerado e inverossímil, em contraponto com a forma mais realista com a qual o seu romance mostra a reabilitação vagarosa de João José Dias:

Se é mulher a doida, rigorosamente desgrenhada, esfrega os olhos, atira com as madeixas para trás, e dá fricções secas às fontes com frenesi; se homem, abre a boca, espanta os olhos, soleva o peito em arquejantes haustos, despede o grito agudo obrigado a ambos os sexos, e está pessoa de juízo. (CASTELO BRANCO, 1967, p.178).

Algumas páginas adiante, a maneira trágica e patética com que os folhetins românticos exploram a descoberta de um adultério é também ridicularizada, ao apresentar-se uma atitude oposta do marido traído, que não mostra grandes preocupações:

Melchior Pimenta saiu do quarto de sua mulher.

Para se armar do punhal de D. Jaime de Bragança, e do infante D. João?

Para se dar um tiro no ouvido? 
Para mergulhar da ponte-pensil, ou despenhar-se dos Arcos-dasVirtudes?

Para cismar e endoidecer?

Não, senhores.

Melchior Pimenta foi para a Alfândega, jantou no hotel Miss Mery, e jogou o voltarete até as onze horas na Assembléia Portuense. (CASTELO BRANCO, 1967, p.181).

Por fim, Camilo encerra o romance com mais um paratexto, um capítulo denominado "Suplemento", no qual novamente trata das relações entre autor e editor: "nada escapa às agulhas da ironia: nem o escritor na sua incômoda posição de dependência, nem o editor na frieza dos seus cálculos, nem a crítica feita por amigos" (COELHO, 1983, p.288).

O narrador-autor conta que seu editor não queria publicar o romance porque "uma virtude em duzentas páginas por quinhentos réis era pequena demais para o comprador que prefere um vício em trezentas" (CASTELO BRANCO, 1967, p.186). Sendo assim, fizeram o "acordo de publicar o magro volume com grandes margens, grandes entrelinhas, exuberância de reticências, e alguns juízos críticos dos meus amigos, que serviriam de indigitar ao leitor em que páginas estão as belezas que ele não viu" (CASTELO BRANCO, 1967, p.187).

Em seguida, o narrador-autor sugere que não precisou utilizar tais artifícios para aumentar o seu romance, uma vez que havia reencontrado Marcos Leite, o amigo que lhe contara a história que lhe inspirou a escrever o livro. Nessa ocasião, Marcos lhe relatou a continuação da história de Ludovina, a qual, por sua vez, o narrador iria informar ao leitor nesse capítulo suplementar.

Podemos desconfiar dessa sugestão, quando pensamos que justamente aquilo que nos chamou a atenção no romance foi seus inúmeros paratextos e comentários digressivos os quais, ao mesmo tempo em que constituem pistas importantes para a construção de uma teoria camiliana da ficção narrativa, como anteriormente explicamos, também servem como matéria escrita para ocupar certo número de páginas que o enredo, por si só, é incapaz de preencher.

Marcos Leite é mais uma paródia do "homem fatal" romântico, que tenta seduzir Ludovina no convento, mas é por ela ignorado. O personagem persegue a protagonista enviando-lhe cartas e poemas românticos, escritos a partir dos lugares-comuns do gênero, chegando a fazer-se de doente para comovê-la. 
O narrador-autor, por sua vez, contrapõe-se a ele, com seu sorriso sarcástico, denunciando a falsidade de tais procedimentos românticos - personificados nesse personagem -, propondo uma visão mais realista de mundo:

- E teimaste?! Seria necessário muito despejo e indignidade!

- Não teimei: caí doente, tive febre, assustei a minha família, e fiz que me chorassem as minhas primas, companheiras conventuais da baronesa [Ludovina] (...).

- Isso devia fundir em lágrimas de remorso a pobre senhora.

- Estás ludibriando a minha angústia? - interrogou Marcos Leite com irônico enfado.

- Não ludibrio a tua angústia, faço a apologia da tua astúcia. Tu não tinhas febre, nem vias a morte à cabeceira do teu leito, fala a verdade.

- Tinha febre, palavra de honra, porque sou muito nervoso; e, se me persuado que tenho uma ponta de febre, sinto-me logo em lavaredas. Tenho tido vinte e tantos destes tifos, com as vinte e tantas mulheres que tu sabes. $O$ que vale é ser rápida e segura a convalescença. (CASTELO BRANCO, 1967, p.199-200).

Ludovina não se deixa enganar pela sedução de Marcos Leite, e sai do convento para cuidar do marido na velhice. Tal final de vida é desprezado por Marcos, o ultraromântico - ou seja, não é digno desse tipo de literatura: “[ela] morrerá estupidamente. Será indigna dum necrológio, e terá apenas uma magra local chamando os amigos do marido a assistirem-lhe aos funerais" (CASTELO BRANCO, 1967, p.212). Com isso, Camilo reafirma o estatuto de verdade do seu romance, como uma maneira de distanciar-se dos modelos literários que buscou parodiar, ridicularizar e criticar ao longo de sua obra.

Como procuramos mostrar no início deste artigo, parece-nos claro que o escritor pressupunha vários tipos de leitores, e um deles era, segundo o narrador-autor de $O$ que fazem mulheres, o provido de inteligência (Cf. CASTELO BRANCO, 1967, p.7). Arriscamos afirmar que esse seria o leitor favorito de Camilo, uma vez que seria para ele - o único capaz de refletir sobre a sua obra e compreendê-la - que o autor construía seu discurso metalingüístico, irônico e paródico, ainda que o outro tipo de leitor aquele que se valeria da resignação (Cf. CASTELO BRANCO, 1967, p.7) - fosse-lhe útil para comprar e consumir seus livros.

Tendo vivido o período de transição entre os dois principais movimentos do século XIX e as mudanças nos campos cultural e discursivo que o acompanharam, 
Camilo nos mostra, através de romances como $O$ que fazem mulheres, uma visão crítica do fazer literário de sua época, como uma forma de distinguir a sua obra do restante da produção oitocentista vigente. Pelo interesse que ainda desperta, mais de um século após a sua morte, podemos afirmar que foi bem-sucedido: o bruxo de Ceide garantira o seu lugar na História.

\section{Referências bibliográficas:}

BOOTH, Wayne C. A Rhetoric of Irony. Chicago and London: The University of Chicago Press, 1974.

CASTELO BRANCO, Camilo. O Que Fazem Mulheres. $8^{\text {a }}$ ed. Lisboa: Parceria A. M. Pereira, 1967.

CASTRO, Aníbal Pinto de. "Para uma teoria camiliana da ficção narrativa". Arquivos do Centro Cultural Português, Lisboa/Paris, v. 29, p. 53-70, 1991.

COELHO, Jacinto do Prado. Introdução ao Estudo da Novela Camiliana. Coimbra: Atlântida, 1946.

. Introdução ao Estudo da Novela Camiliana. $2^{\circ}$ vol., $2^{\mathrm{a}}$ ed. Lisboa: Imprensa Nacional/Casa da Moeda, 1983.

FRANCHETTI, Paulo. “Apresentação”. In: CASTELO BRANCO, Camilo. Coração, Cabeça e Estômago. São Paulo: Martins Fontes, 2003, p. IX-L.

LOURENÇO, Eduardo. "Situação de Camilo". In: O Canto do Signo. Existência e Literatura. Lisboa: Presença, 1994, p. 219-226. 